\title{
Development of a Novel Sodium-Hydrogen Exchanger Inhibitor for Heart Failure
}

\author{
Elizabeth B Juneman ${ }^{1,2}$, Reza Arsanjani ${ }^{2}$, Hoang M Thai ${ }^{1,2}$, Jordan J Lancaster ${ }^{2}$, Jeffrey B Madwed ${ }^{3}$, and \\ Steven Goldman ${ }^{1,2}$ \\ ${ }^{1}$ Section of Cardiology, Department of Medicine, Southern Arizona VA Health Care System, Tucson, AZ, USA \\ ${ }^{2}$ Sarver Heart Center, University of Arizona, Tucson, Arizona, USA \\ ${ }^{3}$ Merck Research Laboratories, Rahway, NJ, USA
}

${ }^{*}$ Corresponding author: Elizabeth Juneman, MD FACC, Associate Professor of Medicine, University of Arizona; SAVAHCS Tucson VA, 3601 South 6th Ave, Section of Cardiology 1-111C, Tucson, AZ 85723, USA, Tel: 520 629 4624; Fax: 520629 4636; E-mail: Selizabeth.juneman@va.gov

Received Date: July 30, 2013, Accepted Date: September 06, 2013, Published Date: September 09, 2013

Citation: Elizabeth Juneman, et al. (2013) Development of a Novel Sodium-Hydrogen Exchanger Inhibitor for Heart Failure. J Cardio Vasc Med 1: 1-6

\begin{abstract}
This study was designed to determine the potential therapeutic effects of a new sodium-hydrogen exchanger (NHE-1) inhibitor in the rat coronary artery ligation model of chronic heart failure. After the induction of acute myocardial infarction, rats were entered into a randomly designed pilot dose study from $0.3 \mathrm{mg} / \mathrm{kg}, 1.0 \mathrm{mg} / \mathrm{kg}$, and $3.0 \mathrm{mg} / \mathrm{kg}$. Solid state micrometer hemodynamics, echocardiographic, and pressure-volume relationships were measured after 6 weeks of treatment. Treatment with this NHE- $\neg 1$ inhibitor at $3 \mathrm{mg} / \mathrm{kg}$ increased $(\mathrm{P}<0.05)$ ejection fraction from $23 \pm 3 \%(\mathrm{~N}=6)$ to $33 \pm 2 \%$ $(\mathrm{N}=13)$, while the $1 \mathrm{mg} / \mathrm{kg}$ dose decreased $(\mathrm{P}<0.05)$ the infarct size in $\mathrm{CHF}$ rats from $21.7 \pm 1.4 \%(\mathrm{~N}=7)$ to $15.9 \pm 0.7 \%(\mathrm{~N}=3)$ and prevented $(\mathrm{P}<0.05)$ dilata $\neg$ tion of the left ventricle in CHF rats in diastole $(1.0 \pm 0.1 \mathrm{~cm}, \mathrm{~N}=6)$ to $0.9 \pm 0.1 \mathrm{~cm}, \mathrm{~N}=10)$ and in systole $(0.9 \pm 0.1 \mathrm{~cm}, \mathrm{~N}=6)$ to $0.8 \pm 0.1, \mathrm{~N}=10)$. These study results suggest that this new NHE- 1 inhibitor may be potentially useful in treating CHF with an improvement in maladaptive left ventricle remodeling. Because the mechanism of action of this agent is entirely different than the currently applied approach in treating CHF that focuses on aggressive neuro-hormonal blockade and because this agent does not adversely affect important hemodynamic variables, further investigations with this agent may be warranted.
\end{abstract}

Keywords: Chronic heart failure; Sodium/hydrogen exchange; Cardiovascular disease; Cardiovascular drugs

Abbreviations: CHF: Chronic Heart Failure; NHE-1: Sodium-Hydrogen Exchanger 1; NCX: Sodium-Calcium Exchanger; $\mathrm{Ca} 2+$ : Calcium; Na+: Sodium; Na+-K+ ATPase: Sodium-Potassium ATPase; NKCC: Sodium-Potassium-Chloride co-transporter; MI: Myocardial Infarction; BI: Boehringer Ingelheim; LV: Left Ventricle; EF: Ejection Fraction; LVD: Left ventricular Dysfunc-tion; PV: Pressure-Volume; SE: Standard Error; ARB: Angiotensin Receptor Blocker ACE: Angiotensin Converting Enzyme

\section{Introduction}

The prevalence and incidence of heart failure continues to grow in Western society and worldwide. There are cur $\neg$ rently more than 5.5 million persons affected with chronic heart failure (CHF) in United States and more than 20 mil $\neg$ lion worldwide [1]. Ischemic cardiomyopathy is the most common cause of systolic heart failure in Western society. Furthermore, CHF poses a significant economic burden accounting for approximately one third of all Medicare spending or about 39.2 billion dollars in the United States in

C2013 The Authors. Published by the JScholar under the terms of the Creative Commons Attribution License http://creativecommons.org/licenses/ by $/ 3.0 /$, which permits unrestricted use, provided the original author and source are credited.

\section{$2010[1]$}

Without reviewing the pathophysiology of CHF here, altered calcium $\left(\mathrm{Ca}^{2+}\right)$ handling is a hallmark of CHF. Intracellular $\mathrm{Ca}^{2+}$ concentration is closely regulated by sodium-calcium exchanger (NCX) and $\mathrm{Ca}^{2+}$ efflux is dependent on the intracellular sodium $\left(\mathrm{Na}^{+}\right)$concentration and trans-sarcolemmal $\mathrm{Na}^{+}$ gradient [2-4]. Multiple channels including sodium-potassium ATPase $\left(\mathrm{Na}^{+}-\mathrm{K}^{+}\right.$ATPase), sodium-hydrogen exchanger (NHE), sodium-bicarbonate co-transporter, sodium-potassium-chloride co-transporter (NKCC), and sodium-magnesium exchanger are responsible for regulation of intracellular sodium in cardiac myocytes $[3,4]$. The intracellular concentration of $\mathrm{Na}^{+}$is significantly increased in heart failure, primarily due to influx of $\mathrm{Na}^{+}$[5-7]. The NHE plays an integral part 
in rise of intracellular $\mathrm{Na}^{+}$concentration and development of hypertrophy in heart failure [8-12]. Because of its multifaceted role in myocardial function, there has been interest in examining the effects of NHE-1 inhibitors in heart failure.

In this study we report the physiologic responses of a new NHE-1 inhibitor, in a rodent model of heart failure. Previous evaluation of the pharmacokinetic properties of this agent in rat and dog models revealed low clearance and robust oral bioavailability, suggesting a potential for once daily oral administration. This new compound was found to be potentially effective in preventing ischemic injury in isolated cells systems and in ischemic injury in isolated cells systems and in a Langendorff isolated heart preparation [13]. Based on these encouraging a pharmacokinetic data, and the established preclinical roof of principle, the next step in new drug development was to test this inhibitor in an appropriate disease-relevant animal model. For this, we chose the rat coronary ligation model of CHF, which is the established model of chronic ischemic heart failure and well performed in our laboratory $[14,15]$. The model with permanent occlusion of the left coronary artery is important because this model a similar to the clinical syn $\neg$ drome of CHF. This rat coronary artery model of CHF is the same model used in the classic study defining the beneficial use of angiotensin converting enzyme inhibition with capto $\neg$ pril in the treatment of CHF [16]. Thus results in this model have the potential to be predictive of the clinical response seen in patients.

\section{Materials and Methods}

\section{Sodium Hydrogen Exporter Inhibitor}

The Sodium Hydrogen Exchanger (NHE-1) Inhibitor was ob-tained from Boehringer Ingelheim (BI). The new NHE1 in-hibitor was identified in lead optimization efforts done by BI intended to identify a potent NHE-1 inhibitor with low poten-tial for drug-drug interactions and a profile suitable for once daily, oral administration. Lead optimization efforts took their starting point in the structure of the NHE-1 inhibitor sabiporide, previously advanced for the treatment of ischemic stroke. A change of the pipirazine linker to piperidine and the replacement of the pyrrole sub-structure to methyl were found to provide improvements in potency, as well as the elimination of off-target activities, such as CYP inhibition; identifying N-[4-(1-acetyl-piperidin-4-yl)-3-trifluoromethyl-benzoyl]guanidine or BIX. Evaluation of the pharmacokinetic properties in rat and dog revealed low clearance and robust oral bioavailability, suggesting a potential for once daily oral administration. Furthermore, the evaluation of BIX in an ex vivo model of ischemia reperfusion injury in isolated rat hearts (Langendorff isolated heart preparation) showed evidence of preventing ischemic damage [13].

\section{Experimental Design}

Adult male Sprague-Dawley rats (8-10 weeks old; Harlan, Indianapolis, IN) were underwent coronary artery ligation. Immediately after creating an acute myocardial infarction (MI) rats were entered into a randomly designed pilot dose rang- ing study at $0.3 \mathrm{mg} / \mathrm{kg}, 1.0 \mathrm{mg} / \mathrm{kg}$, and $3.0 \mathrm{mg} / \mathrm{kg}$ treated for 6 weeks. After initial evaluation of the data for the $0.3 \mathrm{mg} / \mathrm{kg}$, this dose was dropped, so we have limited data with this dose. The food BIX was supplied by BI; formulated on standard rat chow and provided to the rats starting on the day of the MI and continued for 6 weeks. The dose delivered was dependent on the rat consuming a normal amount of food each day, which was monitored. The experiments were performed in an American Association for Accreditation of Laboratory Animal Care accredited facility with approval from the animal use committees of the Southern Arizona Veterans Affairs Health Care System and the University of Arizona (Tucson, AZ).

We performed echocardiograms in the infarcted rats to determine the extent of the MI three weeks post-coronary ligation. Rats with normal left ventriclar ejection fraction (LVEF), no in $\neg$ crease in left ventricle (LV) diastolic dimension and no evidence of anterior myocardial infarction MI by regional wall abnormality were assigned as Sham. Rats with a mild reduction in LVEF, mild increase in LV diastolic dimension and evidence of anterior myocardial infarction MI by regional wall abnormality were assigned as LV dysfunction (LVD). Rats with the greatest decrease in EF, largest LV diastolic dimensions and largest anterior wall MI were assigned as CHF. In our laboratory, a large MI results in approximately $50 \%$ rat mortality. Even though typically rats do not eat for the first 24 hours after MI, this protocol insured that rats received treatment as soon as possible and that the rats with the largest MIs were treated the entire time. We purposely choose rats with the largest infarcts and most damage to the left ventricle, such that these rats had the highest LV end-diastolic pressures. With this approach, we purposely screened for the sickest rats for study, emphasizing the purpose of looking for a signal of therapeutic benefit with this new agent.

\section{Myocardial Infarction Mode 1}

Heart failure was created in rats using standard published techniques from our laboratory [17-22]. In brief, rats were anesthetized with ketamine and acepromazine and a left thoracotomy performed. The heart was expressed from the thorax and a ligature placed around the proximal left coronary artery. The lungs were inflated, the chest closed, and the rat allowed to recover. The rats were maintained on standard rat chow or standard rat chow with drug added as noted above, water ad libitum and pain medication postoperatively. Infarcted rats undergoing this procedure have been documented to have large MIs and CHF [15,23].

\section{Hemodynamics}

Hemodynamics were measured at the end of the treatment period using previously published methods from our laboratory $[14,17,19,20,21]$. In brief, rats were anesthetized with inactin (100 mg/kg intraperitoneal injection) and placed on a specially equipped operating table with a heating pad to maintain constant body temperature. After endotracheal intubation and placement on a rodent ventilator, a $2 \mathrm{~F}$ solid state micromanometer tipped catheter with 2 pressure sensors (Millar, Houston, TX) was inserted via the right carotid artery, with one sensor located in the LV and another in the ascending aorta. 
The pressure sensor was equilibrated in $37^{\circ} \mathrm{C}$ saline before obtaining baseline pressure measurements. After a period of stabilization, LV and aortic pressures, and heart rate were recorded and digitized at a rate of $1000 \mathrm{~Hz}$ using a PC equipped with an analog-digital converter and customized software. From these data, $\mathrm{LV} \mathrm{dP} / \mathrm{dt}$ and the time constant of $\mathrm{LV}$ relaxation (tau) were calculated.

\section{Echocardiography}

Thoracic echocardiography was performed at three weeks post-MI for enrollment and then after 6 weeks of treatment (9 weeks post-MI) to obtain measurements on stroke volume, EF, heart rate, and systolic displacement of the infarcted anterior wall and the non-infarcted posterior wall [20-22]. Images were obtained with $10 \mathrm{MHz}$ transducers in the parasternal short axis view. A Vingmed, Vivid System (GE Ul-trasound) machine was used with EchoPac software. Data were collected using two dimensional M-mode measurements dur $\neg$ ing contraction and relaxation with three cardiac cycles. Sys $\neg$ tolic displacement was calculated using these measurements.

\section{Ejection Fraction and Fractional Shortening}

Using the M-mode parasternal short-axis view from echocardiography, a cursor was placed from the interventricular septum through the left ventricle and posterior wall in minor axis. This was done in diastole and systole. Fractional shortening was calculated by subtracting left ventricular internal dimension in systole from left ventricular internal dimension in diastole. This number was then divided by left ventricular internal dimension in diastole.

\section{Regional Systolic Displacement}

Using parasternal short axis view, 2-dimensional, and M-mode views, we calculated systolic displacement. The M-mode cursor was placed through the anterior and posterior walls during peak systole and peak diastole. This difference in LV wall thickness between systole and diastole of the anterior wall gave the systolic displacement for the anterior wall. This was measured over five cardiac cycles.

\section{Left Ventricular Pressure/Volume Relationships}

LV pressure-volume relations ex-vivo were measured as previously described from our laboratory $[14,15,20,22]$. In brief, at the end of the study, the heart was arrested with potassium chloride, and a catheter consisting of PE-90 tubing with telescoped PE-10 tubing inside was inserted into the LV via the aortic root. One end of the double-lumen LV catheter was connected to a volume infusion pump (Harvard Apparatus, Holliston, MA), whereas the other end was connected to a pressure transducer zeroed at the level of the heart. The right ventricle was partially incised to prevent loading on the LV. The LV was filled $(1.0 \mathrm{~mL} / \mathrm{min})$ to $60-100 \mathrm{~mm} \mathrm{Hg}$ and unfilled while pres $\neg$ sure was recorded onto a physiologic recorder (Gould Instruments, Valley View, $\mathrm{OH}$ ); ischemic time was limited to 10 minutes, the volume infused was a function of filling rate.

\section{Infarct Area}

After the pressure/volume measurements, the heart is fixed at $100 \mathrm{mmHg}$ in $10 \%$ formalin, let sit overnight, and allowed to harden. It is filled with silicon, sliced into 4 sections, 3 faces of these sections are photographed. The outlined of each section is traced defining the outside perimeter, the inside perimeter, and the infarcted area using the NIH developed software (Image J) to obtain measurements infarcted versus normal heart.

\section{Statistical Evaluation}

Data were expressed as mean \pm standard error (SE). For the physiologic and echocardiographic measurements, Student's t-test was used for single comparison of Sham versus other study groups. Interactions were tested using 2-way analysis of variance; intergroup differences were evaluated using the Student-Newman-Keuls test for statistical significance. Pressure-volume relations were evaluated using multiple linear and polynominal regression analysis. The correlation of statistical difference was based on the Durbin-Watson statistic, F-statistic, $\mathrm{P}$ value $(\mathrm{P}<0.05)$, and variance coefficients.

\section{Results}

\section{In vivo Hemodynamic effect of NHE1}

As noted previously by our laboratory, rats with severe CHF compared to sham had changes $(\mathrm{P}<0.05)$ in right ventricular weight, mean arterial pressure, tau, the time constant of LV relaxation, LV systolic pressure, LV end-diastolic pressure, $+\mathrm{LV}$ $\mathrm{dP} / \mathrm{dt},-\mathrm{LV} \mathrm{dP} / \mathrm{dt}$, dead volume and peak developed pres $\neg$ sure $(14,15)$. In this study, treatment resulted in no changes in body weight, chamber weight or hemodynamics (Table 1).

\section{Echocardiographic Changes in LV Function and Dimensions with NHE1}

The data on global LV function and LV dimensions for CHF rats are shown in Figures 1-3. Rats with CHF have decreases in EF accompanied by increases in LV systolic and diastolic dimensions. There was no change in anterior wall systolic dis $\neg$ placement. These data are consistent with other reports in this model showing that at 6 weeks after left coronary artery liga $\neg$ tion, rats with large MIs have dilated left ventricles with LV remodeling and poor LV function $(14,15)$. Treatment with the highest dose of $3 \mathrm{mg} / \mathrm{kg}$ increased $(\mathrm{P}<0.05) \mathrm{EF}$ from $23 \pm 3 \%$ $(\mathrm{N}=6)$ to $33 \pm 2 \%(\mathrm{~N}=13)$. Treatment with $1 \mathrm{mg} / \mathrm{kg}$ prevented maladaptive LV remodeling, it prevented $(\mathrm{P}<0.05)$ dilatation of the LV in CHF rats in diastole $(1.0 \pm 0.1 \mathrm{~cm}, \mathrm{~N}=6)$ to $0.9 \pm 0.1$ $\mathrm{cm}, \mathrm{N}=10)$ and in systole $(0.9 \pm 0.1 \mathrm{~cm}, \mathrm{~N}=6)$ to $0.8 \pm 0.1, \mathrm{~N}=10)$ with no change anterior wall thickening. 


\begin{tabular}{|c|c|c|c|c|c|c|c|c|c|c|c|c|c|}
\hline GROUPS & $\begin{array}{l}\text { BWT } \\
\text { (g) }\end{array}$ & $\begin{array}{l}\mathrm{RV} \\
\text { (g) }\end{array}$ & $\begin{array}{l}\mathrm{LV} \\
(\mathrm{g})\end{array}$ & $\begin{array}{c}\text { LV } \\
\text { WT/ BWT }\end{array}$ & $\begin{array}{c}\mathrm{MAP} \\
(\mathrm{mmHg})\end{array}$ & $\begin{array}{l}\text { TAU } \\
(\mathrm{ms})\end{array}$ & $\begin{array}{c}\mathrm{HR} \\
(\mathrm{bpm})\end{array}$ & $\begin{array}{c}\text { SYS } \\
(\mathrm{mmHg})\end{array}$ & $\begin{array}{l}\text { LV EDP } \\
(\mathrm{mm} \mathrm{Hg})\end{array}$ & $\begin{array}{l}\mathrm{LV}+\mathrm{dP} / \mathrm{dt} \\
(\mathrm{mmHg} / \mathrm{s})\end{array}$ & $\begin{array}{l}\mathrm{LV}-\mathrm{dP} / \mathrm{dt} \\
(\mathrm{mmHg} / \mathrm{s})\end{array}$ & $\begin{array}{l}\text { Dead Volume } \\
\quad(\mathrm{ml})\end{array}$ & $\begin{array}{l}\text { LV PDP } \\
(\mathrm{mmHg})\end{array}$ \\
\hline $\begin{array}{l}\text { Sham } \\
\mathrm{N}=8\end{array}$ & $378 \pm 18$ & $0.18 \pm 0.10$ & $0.80 \pm 04$ & $0.2 \pm 0.1$ & $119 \pm 3$ & $13.9 \pm 1.5$ & $275 \pm 15$ & $136 \pm 3$ & $7 \pm 1$ & $8138 \pm 426$ & $6769 \pm 468$ & $0.19 \pm 0.02$ & $186 \pm 7$ \\
\hline $\begin{array}{l}\text { LVD } \\
\mathrm{N}=4\end{array}$ & $360 \pm 13$ & $0.22 \pm 0.03$ & $0.80 \pm .02$ & $0.2 \pm 0.1$ & $118 \pm 8$ & $18.2 \pm 0.7$ & $252 \pm 17$ & $136 \pm 8$ & $8 \pm 1$ & $6789 \pm 467$ & $5067 \pm 591$ & $0.21 \pm 0.04$ & $163 \pm 10$ \\
\hline $\begin{array}{c}\text { CHF } \\
\mathrm{N}=10\end{array}$ & $350 \pm 9$ & $0.41 \pm 0.03^{*}$ & $0.78 \pm 0.03$ & $0.2 \pm 0.1$ & $99 \pm 3^{*}$ & $24.2 \pm 1.4^{*}$ & $243 \pm 8$ & $110 \pm 3^{*}$ & $26 \pm 1^{*}$ & $4890 \pm 193^{*}$ & $3073 \pm 142^{*}$ & $0.29 \pm 0.03^{*}$ & $118 \pm 3^{*}$ \\
\hline $\begin{array}{c}\text { Sham } \\
\mathrm{NHE}-1 \\
1.0 \mathrm{mg} / \mathrm{kg} \\
\mathrm{N}=6\end{array}$ & $359 \pm 5$ & $0.19 \pm 0.03$ & $0.76 \pm 0.02$ & $0.2 \pm 0.0$ & $119 \pm 1$ & $13.6 \pm 1.2$ & $292 \pm 13$ & $136 \pm 3$ & $5 \pm 1$ & $8337 \pm 430$ & $7205 \pm 550$ & $0.14 \pm 0.01$ & $178 \pm 16$ \\
\hline $\begin{array}{c}\text { LVD } \\
\mathrm{NHE}-1 \\
1.0 \mathrm{mg} / \mathrm{kg} \\
\mathrm{N}=7\end{array}$ & $361 \pm 9$ & $0.20 \pm 0.02$ & $0.80 \pm 0.03$ & $0.2 \pm 0.0$ & $116 \pm 2$ & $20.2 \pm 1.5$ & $266 \pm 7$ & $132 \pm 3$ & $10 \pm 2$ & $6404 \pm 256$ & $4664 \pm 316$ & $0.20 \pm 0.01$ & $154 \pm 9$ \\
\hline $\begin{array}{c}\mathrm{CHF} \\
\mathrm{NHE}-1 \\
1.0 \mathrm{mg} / \mathrm{kg} \\
\mathrm{N}=9\end{array}$ & $360 \pm 9$ & $0.38 \pm 0.01$ & $0.72 \pm 0.03$ & $0.2 \pm 0.0$ & $95 \pm 4$ & $23.0 \pm 1.0$ & $237 \pm 4$ & $108 \pm 5$ & $23 \pm 1$ & $5014 \pm 184$ & $3099 \pm 112$ & $0.22 \pm 0.02$ & $123 \pm 3$ \\
\hline $\begin{array}{c}\text { Sham } \\
\text { NHE-1 } \\
3 \mathrm{mg} / \mathrm{kg} \\
\mathrm{N}=11\end{array}$ & $372 \pm 7$ & $0.23 \pm 0.12$ & $0.82 \pm 0.10$ & $0.2 \pm 0.0$ & $119 \pm 3$ & $13.8 \pm 0.6$ & $275 \pm 9$ & $129 \pm 4$ & $5 \pm 1$ & $7938 \pm 362$ & $6745 \pm 288$ & $0.15 \pm 0.02$ & $197 \pm 6$ \\
\hline $\begin{array}{c}\text { LVD } \\
\mathrm{NHE}-1 \\
3.0 \mathrm{mg} / \mathrm{kg} \\
\mathrm{N}=7\end{array}$ & $368 \pm 7$ & $0.24 \pm 0.01$ & $0.85 \pm 0.03$ & $0.2 \pm 0.0$ & $106 \pm 3$ & $18.5 \pm 1.5$ & $273 \pm 13$ & $121 \pm 4$ & $9 \pm 1$ & $6248 \pm 285$ & $4604 \pm 272$ & $0.24 \pm 0.03$ & $161 \pm 2$ \\
\hline $\begin{array}{c}\mathrm{CHF} \\
\mathrm{NHE}-1 \\
3.0 \mathrm{mg} / \mathrm{kg} \\
\mathrm{N}=9\end{array}$ & $345 \pm 8$ & $0.36 \pm 0.03$ & $0.80 \pm 0.05$ & $0.2 \pm 0.0$ & $100 \pm 4$ & $24.1 \pm 0.9$ & $246 \pm 9$ & $104 \pm 10$ & $23 \pm 2$ & $5069 \pm 260$ & $3288 \pm 204$ & $0.27 \pm 0.01$ & $119 \pm 7$ \\
\hline
\end{tabular}

Body weight (BWT); right ventricular weight (RV); left ventricular weight (LV); LV/body weight ratio (LV WT/BW); left ventricular dysfunction (LVD); mean arterial pressure (MAP); heart rate (HR); LV end-diastolic pressure (EDP); LV peak developed pressure (LV PDP)

${ }^{*} \mathrm{P}<0.05$ Sham versus Severe $\mathrm{CHF}$

Table 1: In Vivo Hemodynamic Measurements

\section{Ejection Fraction - CHF}

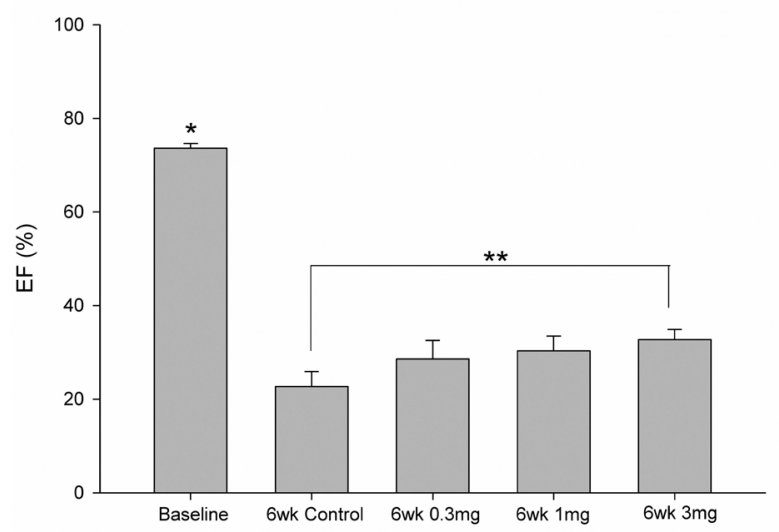

Figure 1: Ejection fraction in CHF rats. Baseline $(\mathrm{N}=36), 6 \mathrm{wk}$ control $(\mathrm{N}=6)$, 6wk 0.3mg $(\mathrm{N}=9)$, 6wk $1 \mathrm{mg}(\mathrm{N}=10)$, 6wk 3mg $(\mathrm{N}=13)$. Data are mean $+\mathrm{SE}$. * denotes statistical significance between baseline and all other groups $(\mathrm{P}<$ $0.05)$. ${ }^{* *}$ denotes statistical significance for intergroup comparison $(\mathrm{P}<0.05)$.

\section{Pressure-Volume relationships}

The pressure-volume (PV) data are presented in Figure 4. Although there are no significant changes in the PV relationships for either the sham or CHF rats, there is a trend for the PV loop in CHF to be shifted toward the pressure axis with treatment. These data are consistent with the trend toward decreases in LV dimensions seen with treatment in CHF rats (Figures 2 and $3)$.

\section{Infarct Size}

At the dose of $1 \mathrm{mg} / \mathrm{kg}$, treatment decreased infarct size $24 \%$ from $21.7 \pm 1.4(\mathrm{~N}=7)$ to $15.9 \pm 0.7(\mathrm{~N}=3)$ in the CHF rats. The changes with the $3 \mathrm{mg} / \mathrm{kg}$ dose, from $16.6 \pm 3.5(\mathrm{~N}=3)$ in the CHF rats were not significantly different but there was a trend toward a decrease in infarct size at this dose. These data sup $\neg$ port a decrease in infarct size in the rats with the largest in $\neg$ farcts with treatment. We did not have enough data in rats with less damage or LVD to analyze.

LV Diastolic Diameter - CHF

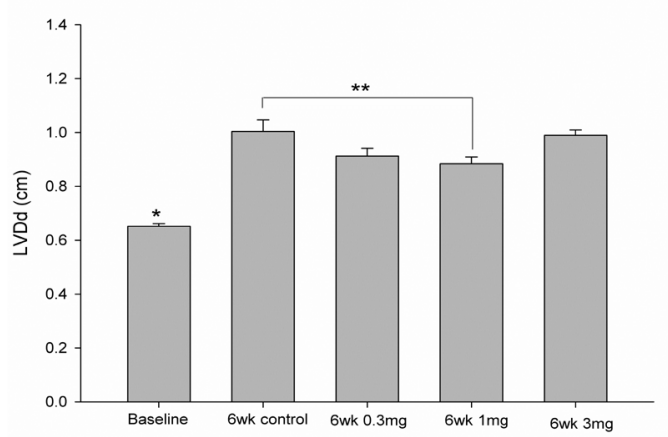

Figure 2: LV diastolic diameter in CHF rats. Baseline $(\mathrm{N}=36)$, 6wk control $(\mathrm{N}=6)$, 6wk 0.3mg $(\mathrm{N}=9)$, 6wk $1 \mathrm{mg}(\mathrm{N}=10)$, 6wk 3mg $(\mathrm{N}=13)$. Data are mean 
$+\mathrm{SE}$. ${ }^{*}$ denotes statistical significance between baseline and all other groups $(\mathrm{P}<0.05){ }^{* *}$ denotes statistical significance for intergroup comparison $(\mathrm{P}<$ $0.05)$.

LV Systolic Diameter - CHF

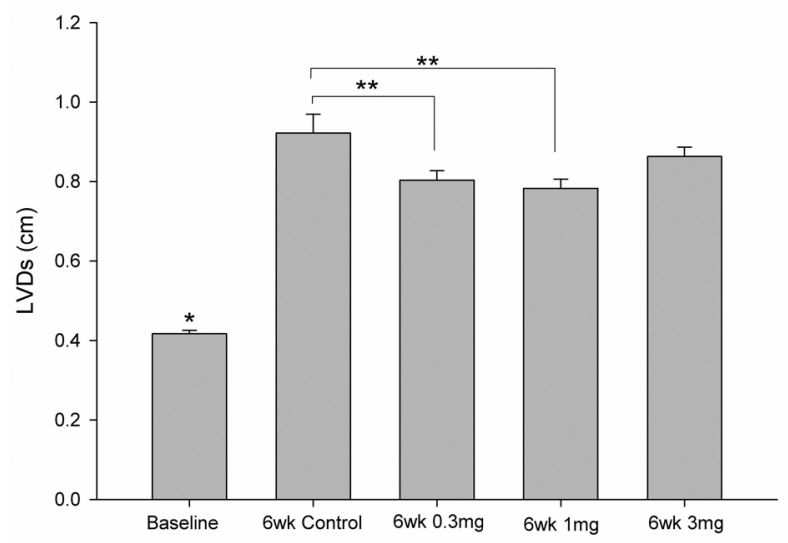

Figure 3: LV systolic diameter in CHF rats. Baseline $(\mathrm{N}=36)$, 6wk control $(\mathrm{N}=6)$, 6wk 0.3mg $(\mathrm{N}=9), 6 \mathrm{wk} 1 \mathrm{mg}(\mathrm{N}=10)$, 6wk $3 \mathrm{mg}(\mathrm{N}=13)$. Data are mean $+\mathrm{SE} .{ }^{*}$ denotes statistical significance between baseline and all other groups $(\mathrm{P}<0.05) .{ }^{*}$ denotes statistical significance for intergroup comparison $(\mathrm{P}<$ $0.05)$.
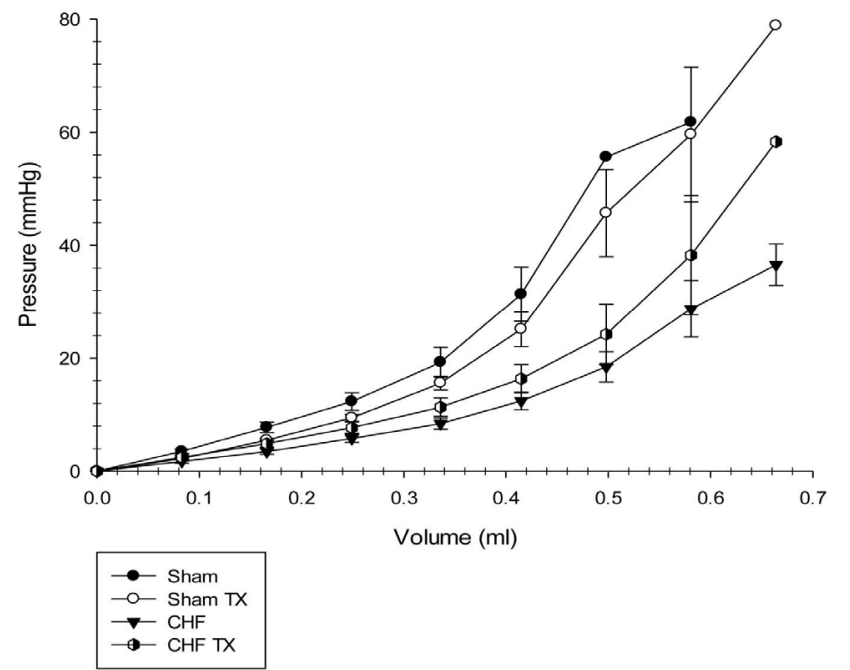

Figure 4: Pressure-volume relationship in Sham $(\mathrm{N}=8)$, Sham $+3 \mathrm{mg}(\mathrm{N}=11)$, $\mathrm{CHF}(\mathrm{N}=10)$, and $\mathrm{CHF}+3 \mathrm{mg}(\mathrm{N}=9)$ rats. There are no significant differences between the curves but with treatment both the sham and appear to show a trend of shifting toward the pressure axis.

\section{Discussion}

This study can be viewed as a corollary of a pilot Phase II clinical trial to look for a signal of a beneficial physiologic effect of this new NHE-1 inhibitor in CHF. In terms of drug development, this is an appropriate approach, i.e., take an agent with a therapeutic focus, with an acceptable toxicology profile, alter its pharmacokinetics to improve its oral delivery and bioavailability and then study the drug in an appropriate animal model. The administration of this agent to rats with $\mathrm{CHF}$ after left coronary artery ligation resulted in a therapeutic benefit with an increase in EF and a decrease in infarct size in rats with the largest infarcts. There is a suggestion of the preven- tion of LV remodeling with decreases in LV end-diastolic and end-systolic dimensions accompanied by a similar trend in the PV loop with a shift toward the pressure axis. There were no changes in hemodynamics

Importantly, the decrease in infarct size with no changes inhemodynamics would positively affect LV remodeling by min imizing LV dilatation without changes in LV afterload. From a therapeutic perspective, an agent like this may be advantageous in the treatment of heart failure after MI. The lack of hemodynamic changes is not a clinical problem because we already have agents that decrease afterload and lower LV enddiastolic pressure such as angiotensin converting enzyme (ACE) inhibitors and angiotensin receptor blockers (ARBs). In treating $\mathrm{CHF}$, we also have diuretics to control blood volume, which in turn reduces LV end-diastolic pressure. The other potential advantage of an NHE-1 inhibitor is that as opposed to our current use of aggressive neuro-hormonal blockade, this represents a different approach to treating CHF. This is attractive because we essentially have exhausted or maximized our effects of neu-ro-hormonal blockade and with no real new treatments for $\mathrm{CHF}$ introduced in the last 10-15 years. We need to look for other approaches to treat CHF.

Drug development is obviously a complicated and expensive undertaking. In exploring this agent, we would propose a stepwise approach. In this case with an agent whose analogs have been studied extensively, our thought would be to perform a larger dose ranging study in CHF rats to define dose response curves for systolic function as well as obtain more information on pharmacokinetics, as well as diastolic function and structural changes.

An attractive aspect of this work is that we are examining an agent with a different mechanisms of action that current treatments for heart failure. The stimulus to study the agent in an animal model of heart failure was based on multifaceted roles of sodium-hydrogen exchangers on myocardial function. Nine isoforms of NHE have currently been identified, with NHE-1 being the predominant isoform in the plasma membrane of the myocardium $[3,24]$. Because NHE is activated by intracel $\neg$ lular acidosis, angiotensin II, and catecholamines, its activity is expectedly increased in heart failure [9,25-27]. Inhibition of NHE-1 has previously been associated with decreased fibrosis, apoptosis, preserved contractility, and attenuation of hypertrophy and development of heart failure [9,10,24,28].

\section{Limitations}

There are some potential limitations to this work; the most obvious is that no animal model is able to really define response to a drug in patients with disease. In addition, we only studied a few doses of the drug without accompanying pharmacokinetic data. In this study, we concentrated on the sickest animals with the largest infarcts, we did not study moderate heart failure animals and we did not explore drug given prior to the infarct as prophylactic approach. 


\section{Conclusion}

We investigated the role of a new NHE-1 inhibitor in the rat coronary artery ligation model of CHF. This agent had a beneficial effect by preventing adverse LV remodeling, improving EF without altering afterload. There are enough positive data here to encourage us to expand our investigation of this new drug potentially looking at a larger animal model of CHF.

\section{Competing Interests}

The authors have no conflict of interest as it pertains to this manuscript.

\section{Acknowledgements}

We thank Nichole Johnston BS, Maribeth Stansifer BS, and Howard Byrne for their technical assistance and Drs. Anne Eldrup and Jeff Madwed from Boehringer Ingelheim Pharmaceuticals, Inc. for their advice.

\section{Funding}

This study was supported in part by grant support from Boehringer Ingelheim, the Department of Veterans Affairs, the WARMER Foundation, the Hansjörg Wyss Foundation, and the Biomedical Research and Education Foundation of Southern Arizona. The drug was supplied in the rat chow by Boehringer-Ingelheim.

\section{References}

1) Lloyd-Jones D, Adams RJ, Brown TM, Carnethon M, Dai S, et al. (2010) Executive Summary: Heart Disease and Stroke Statistics--2010 Update: A Report From the American Heart Association. Circulation 121: 948-954.

2) Eisner DA, Isenberg G, Sipido KR (2003) Normal and Pathological Excitation- Contraction Coupling in the Heart -- an Overview. J Physiol 546: 03-04.

3) Baartscheer A, van Borren MMGJ (2008) Sodium Ion Transporters as New Therapeutic Targets in Heart Failure. Cardiovasc Hematol Agents Med Chem 6: 229-236.

4) Murphy E, Eisner DA (2009) Regulation of Intracellular and Mitochondrial Sodium in Health and Disease. Circ Res 104: 292-303

5) Despa S, Islam MA, Weber CR, Pogwizd SM, Bers DM (2002) Intracellular $\mathrm{Na}(+)$ Concentration is Elevated in Heart Failure but $\mathrm{Na} / \mathrm{K}$ Pump Function is Unchanged. Circulation 105: 2543-2548.

6) Baartscheer A, Schumacher CA, van Borren MMGJ, Belterman CNW, Coronel R, et al. (2003) Increased $\mathrm{Na}+\mathrm{H}+$-Exchange Activity is the Cause of Increased $[\mathrm{Na}+] \mathrm{i}$ and Underlies Disturbed Calcium Handling in the Rabbit Pressure and Volume Overload Heart Failure Model. Cardiovasc Res 57: 1015-1024.

7) Pieske B, Houser SR (2003) [ $\mathrm{Na}+]$ i Handling in the Failing Human Heart. Cardiovasc Res 57: 874-886.

8) Engelhardt S, Hein L, Keller U, Klämbt K, Lohse MJ (2002) Inhibition of $\mathrm{Na}(+)-\mathrm{H}(+)$ Exchange Prevents Hypertrophy, Fibrosis, and Heart Failure in Beta(1)- Adrenergic Receptor Transgenic Mice. Circ Res 90: 814-819.

9) Chen L, Chen CX, Gan XT, Beier N, Scholz W, et al. (2004) Inhibition and Reversal of Myocardial Infarction-Induced Hypertrophy and Heart Failure by NHE-1 Inhibition. Am J Physiol Heart Circ Physiol 286: 381-387.

10) Marano G, Vergari A, Catalano L, Gaudi S, Palazzesi S, et al. (2004) Na+l $\mathrm{H}+$ Exchange Inhibition Attenuates Left Ventricular Remodeling and Preserves Systolic Function in Pressure-Overloaded Hearts. Br J Pharmacol 141: 526-532.

11) Baartscheer A, Schumacher CA, van Borren MMGJ, Belterman CNW, Coronel R, et al. (2005) Chronic Inhibition of $\mathrm{Na}+\mathrm{H}+-$ Exchanger Attenu- ates Cardiac Hypertrophy and Prevents Cellular Remodeling in Heart Failure. Cardiovasc Res 65: 83-92.

12) Cingolani HE, Ennis IL (2007) Sodium-hydrogen exchanger, cardiac overload, and myocardial hypertrophy. Circulation 115: 1090-1100.

13) Huber JD, Bentzien J, Boyer SJ, Burke J, DeLombaert S, et al. (2012) Identification of a potent sodium hydrogen exchanger isoform 1 (NHE1) inhibitor with a suitable profile for chronic dosing and demonstrated cardioprotective effects in a preclinical model of myocardial infarction in the rat. J Med Chem 55: 7114-7140

14) Goldman S, Raya TE (1995) Rat Infarct Model of Myocardial Infarction and Heart Failure. J Card Fail 1: 169-177.

15) Gaballa MA, Goldman S (2002) Ventricular Remodeling in Heart Failure. J Card Fail. 8: 476-485.

16) Pfeffer MA, Pfeffer JM, Steinberg C, Finn P (1985) Survival After Experimental Myocardial Infarction: Beneficial Effects of Long-Term Therapy with Captopril. Circulation 72: 406-412.

17) Raya TE, Gay RG, Aguirre M, Goldman S (1989) Importance of Venodilatation in Prevention of Left Ventricular Dilatation after Chronic Large Myocardial Infarction in Rats: A Comparison of Captopril and Hydralazine. Circ Res 64: 330-337.

18) Gaballa MA, Raya TE, Goldman S (1995) Large Artery Remodeling After Myocardial Infarction. Am J Physiol 268: 2092-2103.

19) Raya TE, Gaballa M, Anderson P, Goldman S (1997) Left Ventricular Function and Remodeling after Myocardial Infarction in Aging Rats. Am J Physiol 273: 2652-2658.

20) Thai H, Castellano L, Juneman E, Phan H, Do R, et al. (2006) Pretreatment with Angiotensin Receptor Blockade Prevents Left Ventricular Dysfunction and Blunts Left Ventricular Remodeling Associated with Acute Myocardial Infarction. Circulation 114: 1933-1939.

21) Thai HM, Juneman E, Lancaster J, Hagerty T, Do R, et al. (2009) Implantation of a Three-Dimensional Fibroblast Matrix Improves Left Ventricular Function and Blood Flow After Acute Myocardial Infarction. Cell Transplant 18: 283-295.

22) Lancaster JL, Juneman E, Hagerty T, Do R, Hicks M, et al. (2010) Viable Fibroblast Matrix Patch Induces Angiogenesis and Increases Myocardial Blood Flow in Heart Failure after Myocardial Infarction. Tissue Eng.Part A 16: $3065-3073$

23) Pennock GD, Raya TE, Bahl JJ, Goldman S, Morkin E (1993) Combination Treatment with Captopril and the Thyroid Hormone Analogue 3,5- Diiodothyropropionic Acid. A New Approach to Improving Left Ventricular Performance in Heart Failure. Circulation 88: 1289-1298.

24) Karmazyn M, Sawyer M, Fliegel L (2005) The $\mathrm{Na}(+) / \mathrm{H}(+)$ Exchanger: A Target for Cardiac Therapeutic Intervention. Curr Drug Targets Cardiovasc Haematol Disord 5: 323-335.

25) Takewaki S, Kuro-o M, Hiroi Y, Yamazaki T, Noguchi T, et al. (1995) Activation of $\mathrm{Na}(+)-\mathrm{H}+$ Antiporter (NHE-1) Gene Expression During Growth, Hypertrophy and Proliferation of the Rabbit Cardiovascular System. J Mol Cell Cardiol 1995, 27: 729-742.

26) Avkiran M, Haworth RS (2003) Regulatory Effects of G Protein-Coupled Receptors on Cardiac Sarcolemmal Na+/H+ Exchanger Activity: Signalling and Significance. Cardiovasc. Res 57: 942-952.

27) Dulce RA, Hurtado C, Ennis IL, Garciarena CD, Alvarez MC, et al. (2006) Endothelin-1 Induced Hypertrophic Effect in Neonatal Rat Cardiomyocytes: Involvement of $\mathrm{Na}+/ \mathrm{H}+$ and $\mathrm{Na}+/ \mathrm{Ca} 2+$ Exchangers. J Mol Cell Cardiol 41 807-815.

28) Spitznagel H, Chung O, Xia Q, Rossius B, Illner S, et al. (2000) Cardioprotective Effects of the $\mathrm{Na}(+) / \mathrm{H}(+)$ - Exchange Inhibitor Cariporide in InfarctInduced Heart Failure. Cardiovasc Res 46: 102-110. 